\title{
Indicadores anatômicos de dominância entre as artérias coronárias em caprinos
}

João Leão Pinto Neto ${ }^{1}$

Carlos Eduardo Silva LEÃO' ${ }^{1}$

Tiago Henrique Marçal

VIEIRA $^{1}$

Adalgizza Kelly Melo Silva

LOPES 1

Saulo Rodrigues Conceição VIEIRA ${ }^{1}$

Nailton Cavalcante da

SILVA ${ }^{2}$

Gabriela Cavallini WAFAE ${ }^{3}$

Cristiane Regina RUIZ ${ }^{4}$

Nader WAFAE ${ }^{5}$

\section{Correspondência para:}

Cristiane Regina Ruiz, Rua Roberto Koch, 34, São Paulo-SP, 04221-060 e-mail: crisruiz@saocamilo-sp.br

Recebido para publicação: 22/11/2007 Aprovado para publicação: 28/08/2008

\author{
1 - Curso de Medicina da Universidade do Planalto Central, Brasília-DF \\ 2 - Laboratório de Anatomia da Universidade do Planalto Central, Brasília-DF \\ 3 - Curso de Medicina da Universidade Nove de Julho, São Paulo-SP \\ 4 - Centro Universitário São Camilo, São Paulo-SP \\ 5 - Centro Universitário São Camilo, São Paulo-SP e Universidade do Planalto \\ Central, Brasília-DF
}

\section{Resumo}

O interesse crescente em se utilizar artérias coronárias de caprinos em experiências como uma etapa para sua aplicação em coronárias humanas justifica o conhecimento anatômico mais detalhado dessas artérias principalmente para se avaliar as semelhanças e as diferenças. Em corações humanos utilizando-se a crux cordis e a procedência do ramo interventricular posterior como referências consideram-se três tipos de padrões: dominância direita, balanceada e dominância esquerda. No entanto, não encontramos citações na literatura sobre os indicadores anatômicos de dominância coronária em caprinos. Material e método: Utilizamos 31 corações de caprinos de ambos os sexos, fixados em formalina a $10 \%$. Os ramos das artérias coronárias eram dissecados com especial atenção para os níveis considerados como referências. $\mathrm{O}$ ramo presente no interior do sulco interventricular subsinuoso procedia do ramo circunflexo, ramo da artéria coronária esquerda. O ramo interventricular subsinuoso apresentou pelo menos um pequeno ramo que ultrapassava a crux cordis. A região do ápice apresentou predominância dos ramos da artéria coronária esquerda: interventricular paraconal e interventricular subsinuoso. A artéria coronária esquerda, através de seus ramos, também predominou no comprimento total e na emissão de ramos ventriculares inclusive para o ventrículo direito. Utilizando como referências os diversos critérios inclusive, os propostos por esta pesquisa, concluímos que em corações de caprinos o padrão arterial é dominância esquerda. A diversidade em relação ao padrão arterial entre caprinos e humanos requer que nas experiências efetuadas, em coronárias de caprinos, essa importante diferença seja observada.

\section{Introdução}

$\mathrm{O}$ interesse de pesquisadores em utilizar as artérias coronárias de caprinos em experiências: hiperemia reativa na circulação coronária ${ }^{1,2}$, ações de fármacos em coronárias ${ }^{3,4}$, vasodilatação coronária induzida ${ }^{5}$, insuficiência cardíaca após ligadura da artéria coronária ${ }^{6}$, modelos experimentais de infarto agudo do miocárdio $^{7}$ visando a aplicação em corações humanos justifica o conhecimento anatômico mais detalhado destas artérias.

mais detalhado destas artétias.
Palavras-chave: Artérias coronárias. Anatomia de caprinos. Vascularização do coração. Artéria dominante.
Um aspecto sobre o qual não encontramos citações na literatura consultada refere-se à discussão sobre critérios dos indicadores anatômicos para a possível dominância entre as artérias coronárias nos corações de caprinos.

Em corações humanos, inicialmente, foi sugerido $^{8}$ como indicador de referência de dominância, a artéria coronária que fornecesse o ramo interventricular posterior e emitisse ramos que ultrapassassem a crux cordis, (ponto de encontro entre os sulcos interatrial, 
interventricular posterior e coronário). Desde então, outros critérios tem sido sugeridos: relação de comprimento entre as artérias: coronária direita e ramo circunflexo ou a relação entre os ramos marginais ${ }^{9}$, participação das artérias no ápice do coração $\mathrm{o}^{10}$, comprimento da artéria interventricular anterior ${ }^{11}$.

\section{Material e Método}

O material utilizado nesta pesquisa consta de 31 corações de caprinos, SRD, de ambos os sexos, pesando entre 76,5 e 107,7 g fixados e conservados em formalina a $10 \%$.

Após a retirada do coração do interior do tórax do animal procedíamos à lavagem da peça. As artérias coronárias eram identificadas, em algumas peças, para melhor exposição das artérias e de seus ramos, injetamos através da aorta, neoprene látex na cor vermelha. Em seguida, procedíamos à dissecação das artérias até as terminações macroscopicamente visíveis dos seus ramos, sob o pericárdio.

A biometria era efetuada, utilizando um fio metálico estendido ao longo das artérias e de seus ramos para em seguida ser transferido a um paquímetro universal mecânico Digimess no 703032 no qual fazíamos a medição.

\section{Resultados}

A fim de reunir elementos que possam esclarecer a dominância entre as artérias coronárias nos concentramos nos seguintes locais: sulco interventricular subsinuoso (sulco interventricular posterior), crux cordis (ponto de encontro dos sulcos: coronário, interventricular subsinuoso e interatrial), ápice do coração e margens ventriculares. Outro indicativo analisado e que estamos propondo, consiste em verificar o número total de ramos ventriculares emitidos por ambas as artérias coronárias.

O sulco interventricular subsinuoso esteve sempre ocupado por ramos da artéria coronária esquerda. Essa ocupação podia ser pelo ramo interventricular subsinuoso enquanto terminação da artéria circunflexa, ou pela própria artéria circunflexa ou ainda pelo ramo interventricular paraconal. Foram observadas as seguintes disposições: aramo interventricular subsinuoso longo ocupando a maior parte do sulco interventricular subsinuoso, em 14 casos ou $45,2 \%$; b- ramo interventricular subsinuoso curto acompanhado por uma das subdivisões do ramo circunflexo que ocupavam a maior parte do sulco interventricular subsinuoso e a parte inferior ocupada pela artéria interventricular paraconal, em 11 peças ou $35,5 \%$; c- dois ramos emitidos pelo ramo circunflexo, ambos ocupando o sulco interventricular subsinuoso, em 6 casos ou 19,3\% (Figuras 1 e 2).

Em todos os casos, o ramo circunflexo da artéria coronária esquerda chegava até a crux cordis (100,0\%), ponto de encontro dos sulcos: interatrial, interventricular subsinuoso e coronário

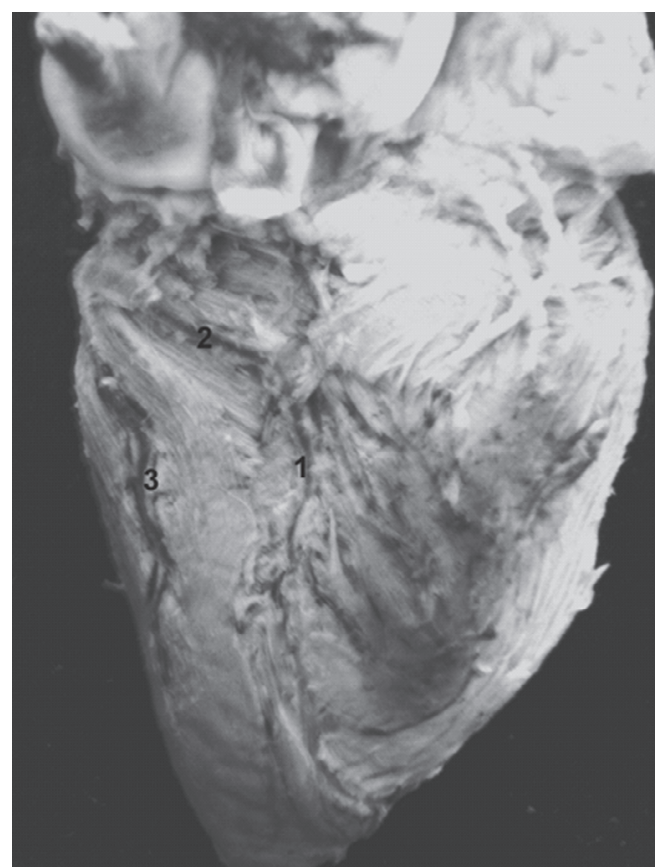

Figura 1 - Coração de caprino demonstrando as artérias: 1 - ramo interventricular subsinuoso longo 2- ramo circunflexo 3- ramo do ramo circunflexo para o ventriculo direito 


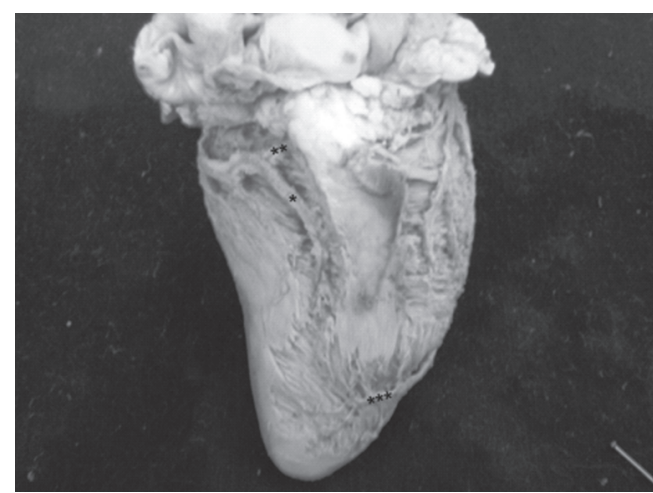

Figura 2 - Coração de caprino demonstrando sulco interventricular subsinuoso com a presença do ramo interventricular subsinuoso do ramo circunflexo nos dois terços superiores $(*)$ ramo interventricular paraconal do terço posterior $(* * *)$, ramo ultrapassando a crux cordis $(* *)$

podendo cruzá-la diretamente $(38,7 \%)$ ou através de ramos $(48,3 \%)$. O número desses ramos variou de 1 a 3 sendo um, o mais freqüente $(61,3 \%)$. Nestes casos, o ramo podia ser curto $(81,5 \%)$ ou longo $(18,5 \%)$.

A artéria coronária direita não atingia a crux cordis em $92,6 \%$ dos casos e mesmo nos dois corações $(7,4 \%)$ em que chegou a crux cordis, sua participação na formação do ramo interventricular subsinuoso era insipiente (Figura 3).

Os ramos presentes no ápice do coração sempre pertenceram aos ramos da artéria coronária esquerda.

O ramo interventricular paraconal terminava seu trajeto subpericárdico antes de atingir o ápice do coração em 16,1\%,

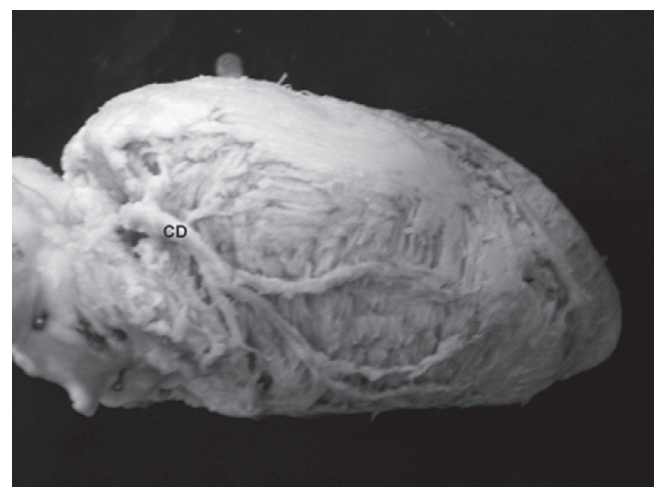

Figura 3 - Coração de caprino demonstrando a artéria coronária direita $(\mathrm{CD})$ terminando antes da crux cordis no próprio ápice em $25,8 \%$ ou então passava pelo ápice e terminava no sulco interventricular subsinuoso em 58,1\%, destes, $37 \%$ iam até o terço médio e $21,1 \%$ terminavam no terço inferior desse sulco (Figura 4).

O ramo interventricular subsinuoso podia terminar antes de atingir o ápice do coração $(67,7 \%)$ ou no próprio ápice $(32,3 \%)$.

O ramo marginal do ventrículo esquerdo, quando presente $(35,5 \%)$, também podia terminar no ápice $(16,2 \%)$.

Embora a artéria coronária direita emitisse vários ramos para a face direita, observamos apenas em $12,9 \%$ um vaso com as características de localização e de extensão correspondendo ao ramo marginal do ventrículo direito e em nenhum caso chegou ao ápice.

Os comprimentos médios das artérias do coração foram: coronária direita $-60 \mathrm{~mm}$ (valores extremos: $35-$ $86 \mathrm{~mm}$ ), já a coronária esquerda

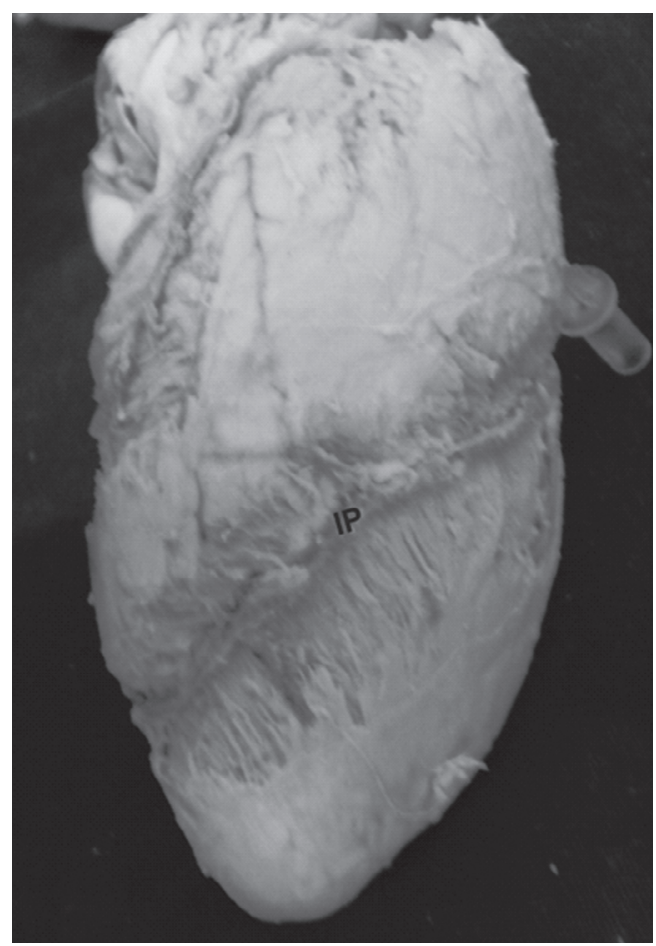

Figura 4 - Coração de caprino demonstrando o ramo interventricular paraconal (IP) passando pelo ápice e terminando no sulco interventricular subsinuoso 
participou com seus ramos: interventricular paraconal - $105 \mathrm{~mm}$ (valores extremos: $80-124 \mathrm{~mm}$ ), circunflexa - $82 \mathrm{~mm}$ (valores extremos: $64-115 \mathrm{~mm}$ ), interventricular subsinuoso - $31 \mathrm{~mm}$ (valores extremos: 5 - $51 \mathrm{~mm}$ ).

Considerando a totalidade das peças estudadas, a artéria coronária esquerda através de seus ramos: interventricular paraconal e circunflexo (incluindo o ramo interventricular subsinuoso), emitiu 662 ramos $(85 \%)$ e a coronária direita 117 ramos (15\%). Enquanto a artéria coronária direita participava no total das peças com 151 ramos $(36 \%)$ do suprimento arterial para o ventrículo direito, a coronária esquerda participava com 269 ramos (64\%) para esse mesmo ventrículo. Em cada coração o número médio de ramos ventriculares emitidos pela coronária esquerda foi de 25 (extremos: 12 - 44) e pela a coronária direita, de 5 (extremos: 3 -9).

\section{Discussão}

A utilização da artéria que diretamente ou através de seus ramos curtos ou longos ultrapasse a crux cordis e a procedência do ramo interventricular subsinuoso como as referências mais admitidas $^{8,12}$ para se determinar a artéria dominante em humanos são também os critérios que definem melhor a artéria dominante do coração em caprinos. Considerando esses parâmetros, o padrão arterial do coração de caprinos é de dominância esquerda (100\%). Falci Junior et al. ${ }^{12}$ pesquisando em corações humanos, atribuem especial importância ao número de ramos que ultrapassaram a crux cordis e observaram um ramo em $48 \%$ das peças. Em caprinos encontramos um único ramo em $61,3 \%$ dos corações e podia ser curto $(81,5 \%)$ ou longo $(18,5 \%)$, estes com mais de $10 \mathrm{~mm}$.

Nos caprinos, todos os demais critérios citados na literatura como parâmetros possíveis confirmaram a dominância esquerda. Os ramos presentes no ápice do coração sempre pertenceram aos ramos da artéria coronária esquerda. O ramo marginal do ventrículo esquerdo predominou em relação à margem direita.

Os critérios sugeridos nesta pesquisa; diferença na soma dos comprimentos das artérias e número de ramos emitidos também demonstrou evidente dominância esquerda. Da totalidade das somas dos comprimentos dos ramos emitidos pelas artérias, a coronária esquerda revelou $78,4 \%$ e a coronária direita apenas $21,6 \%$ e o número de ramos ventriculares apontou $83 \%$ emitidos pela coronária esquerda e 17\% pela coronária direita.

Nos humanos, a dominância é da coronária direita: $73,5 \%{ }^{13}, 70 \%{ }^{14}, 89 \% 0^{15}$, $68 \%{ }^{12}, 60 \%{ }^{16}$. Assim, parece-nos que a utilização experimental de artérias coronárias de caprinos visando sua aplicação em artérias coronárias humanas deve merecer uma análise mais aprofundada. Por exemplo, utilizá-las em processos experimentais que não teriam seus objetivos diretamente relacionados com futura aplicação nas artérias coronárias humanas ou em suas áreas de abrangência. Não encontramos, na literatura consultada, pesquisas que tenham seguido o mesmo modelo para comparação de resultados, já que Lipovetsky et al. ${ }^{17}$ se limitaram a confirmar a dominância esquerda nos caprinos e a diferença com a dominância direita em humanos.

Pode-se concluir que o ramo interventricular paraconal é ramo da artéria coronária esquerda e ultrapassa a crux cordis através de seus ramos; a presença do ramo interventricular anterior no ápice do coração é predominante; a emissão de ramos ventriculares, inclusive para o ventrículo direito, é predominantemente pela coronária esquerda; no coração de caprinos a artéria coronária esquerda é dominante e o padrão de suprimento arterial em corações de caprinos é diferente do padrão de suprimento arterial em corações humanos. 


\section{Anatomical indicators of dominance among the coronary arteries in goats}

\section{Abstract}

The growing interest in the use of coronary arteries of goats in researches to posterior application in human hearts justifying the more detailed anatomical knowledge of this arteries mainly to evaluate their similarities and differences with the human arterial pattern. However, we not found anatomical studies on indicators of coronary dominance in goats. In the literature, we found only the definition of three kinds of pattern in human hearts: right dominance, balanced and left dominance. To this work we used 31 goats hearts, of both sexes and fixed and conserved in formalin at 10\%. The branches of coronary arteries were dissected with special attention to the levels considered as references. The branch present in the interventricular subsinuosis sulcus had origin in the circumflex branch that is a branch of the left coronary artery. The interventricular subsinuosis branch presented at least a little branch that exceeded the crux cordis. The region of the apex presented predominance of the left coronary artery branches: interventricular paraconalis and interventricular subsinuosis. The left coronary artery, through their branches, also dominated in total length and the issue to ventricular branches including for the right ventricle. Using references to various criteria including, those proposed for this research, we find that in goats hearts the arterial pattern is left dominance. The diversity in relation to the arterial pattern between goats and humans requires that in the experiments performed in the coronary goats, this important difference is observed.

\section{Key words:}

Coronary arteries.

Goats anatomy.

Vascularization of heart.

Dominant arteries.

\section{Referências}

1 FERNANDEZ, N.; MONGE, L.; GARCIAVILLALON, A. L.; DIEGUEZ, G. Coronary reactive hyperaemia and arterial pressure in anesthetized goats. Exp. Physiol., v. 91, n. 5, p. 915-923, 2006.

2 CLIMENT, B.; FERNANDEZ, N.; SANCHEZ, A.; GARCIA-VILLALON, A. L.; MONGE L.; DIEGUEZ G. Vasoconstrictor prostanoids may be involved in reduced coronary reactive hyperaemia after ischemiareperfusion in anesthetized goats. Eur J Pharmacol., V. 530, N. 3, P. 234-242, 2006.

3 FERNANDEZ, N.; MARTINEZ, M.A.; GARCIAVILLALON, A. L.; MONGE, L.; DIEGUEZz, G. Coronary effects of endothelin-1 and vasopressin during acute hypotension in anesthetized goats. Life Sci., v. 77, n. 4, p. 423-434, 2005.

4 DIEGUEZ, G.; MARTINEZ, M. A.; FERNANDEZ, N.; CLIMENT, B.; GARCIA-VILLALON, A. L.; MONGE, L. Vasopressin effects on the coronary circulation after a short ischemia in anesthetized goats: role of nitric oxide and prostanoids. Eur J Pharmacol., v.495, n. 2/3, p. 171-177, 2004.

5 DEKA, D. K.; RAVI PRAKASH, V.; MISHRA, S. K. Sodium nitroprusside relaxes goat coronary artery through activation of calcium-dependent $K+$ channels. Indian J Exp Biol., v. 43, n. 3, p. 324-329, 2005.
6 KIM, W. G.; CHO, S. R.; SUNG S. H.; PARK, H. J. A chronic heart failure model by coronary artery ligation in the goat. Int J Artif Organs, v. 26, n.10 p.929-934, 2003.

7 SHIRAKAWA, Y.; SAWA, Y.; TAKEWA, Y.; TATSUMI, E.; KANEDA, Y.; TAENAKA, Y.; MATSUDA, $\mathrm{H}$. Gene transfection with human hepatocyte growth factor complementary DNA plasmids attenuates cardiac remodeling after acute myocardial infarction in goat hearts implanted with ventricular assist devices. J Thorac Cardiovasc Surg., v. 130, n. 3, p. 624-632 , 2005.

8 SCHELESINGER, M. J. Relation of the anatomic pattern to pathologic conditions of the coronary arteries. Arch. Pathol., v. 30, p. 403-415, 1940.

9 BAROLDI, G.; SCOMAZZONI, G. Coronary circulation in the normal and the pathologic heart. Washington, D.C.: Office of the surgeon general, Department of the Army. 1967.

10 JAMES, T. N. Anatomy of the coronary arteries. New York: Paul B. Hoeber, 1961.

11 ILIA, R.; ROSENSHTEIN, G.; WEINSTEIN, J.; CCAFRI, C.; ABU-FUL, A.; GUERON, M. Left anterior descending artery length in left and right coronary artery dominance. Coron Artery Dis., v. 12, n. 1, p. 77-78, 2001.

12 FALCI JUNIOR, R.; GUIMARÃES, M. H.; SANTOS, A. P. S.; CABRAL, R. H.; JATENE, F. B.; PRATES, N. E. 
V. B. Estudo comparativo do padrão de circulação coronariana entre peças anatômicas e pacientes cirúrgicos. Rev. Hosp. Clin. Fac. Med. S.Paulo, v. 51, n.6, p. 224-227, 1996.

13 DIDIO, L. J.; WAKEFIELD, T. W. Coronary arterial predominance or balance on the surface of the human cardiac ventricles. Anat. Anz., v. 137, n. 1/2, p. 147158, 1975.

14 CAVALCANTI, J. S.; OOLIVEIRA M. L.; MELO JUNIOR, A. V. P.; BALABAN G.; OLIVEIRA, C. L. A.; LUCENA, E. O. Anatomic variations of the coronary arteries. Arq Bras Cardiol, v. 65, n. 6, p. 489-492, 1995.

15 NERANTZIS, C. E.; PAPACHRISTOS, J. C.; GRIBIZI, J. E.; VOUDRIS, V. A.; INFANTIS G. P.; KOROXENIDIS, G. T. Functional dominance of the right coronary artery: incidence in the human heart. Clin. Anat, v. 9, n. 1, p. 10-13, 1996.

16 KAIMKHANI, Z. A.; ALI, M. M.; FARUQI, A. M. Pattern of coronary arterial distribution and its relation to coronary artery diameter. J. Ayub Med. Coll. Abbottabad,v. 17, n. 1, p. 40-43, 2005

17 LIPOVETSKY, G.; FENOGLIO, J. J.; GIEGER, M.; SRINIVASAN, M. R.; DOBELLE, W. H. Coronary artery anatomy of the goat. Artif. Organs, v. 7, n. 2, p. 238245, 1983. 